\title{
Swimming induced pulmonary oedema in athletes - a systematic review and best evidence synthesis
}

\author{
Erik Hohmann ${ }^{1,2,3^{*}}$, Vaida Glatt ${ }^{4}$ and Kevin Tetsworth ${ }^{5,6,7}$
}

\begin{abstract}
Background: Swimming induced pulmonary oedema is an uncommon occurrence and usually presents during strenuous distance swimming in cold water. The prevalence is most likely underreported and the underlying mechanisms are controversial. The purpose of this study was to summarize the evidence with regards to prevalence, pathophysiology and treatment of swimming induced pulmonary oedema in endurance athletes.

Methods: Medline, Embase, Scopus and Google Scholar were searched and level I-IV from 1970 to 2017 were included. For clinical studies, only publications reporting on swimming-induced pulmonary oedema were considered. Risk of bias was assessed with the ROBINS-I tool, and the quality of evidence was assessed with the Cochrane GRADE system. For data synthesis and analysis, a best evidence synthesis was used.

Results: A total of 29 studies were included (174 athletes). The most common symptom was cough, dyspnoea, froth and haemoptysis. The risk of bias for the clinical studies included 13 with moderate risk, 3 with serious, and 4 with critical. Four of the pathophysiology studies had a moderate risk, 3 a serious risk, and 1 a critical risk of bias. A best evidence analysis demonstrated a strong association between cold water immersion and in increases of CVP (central venous pressure), MPAP (mean pulmonary arterial pressure), PVR (peripheral vascular resistance) and PAWP (pulmonary arterial wedge pressure) resulting in interstitial asymptomatic oedema.

Conclusion: The results of this study suggest a moderate association between water temperature and the prevalence of SIPE. The presence of the clinical symptoms cough, dyspnoea, froth and haemoptysis are strongly suggestive of SIPE during or immediately following swimming. There is only limited evidence to suggest that there are pre-existing risk factors leading to SIPE with exposure to strenuous physical activity during swimming. There is strong evidence that sudden deaths of triathletes are often associated with cardiac abnormalities.
\end{abstract}

Keywords: Pulmonary oedema, Immersion pulmonary oedema, SIPE, Swimming, Athletes, Triathlon

\section{Introduction}

The question as to whether pulmonary oedema can develop during exercise in humans remains controversial [1]. It is a well-recognised condition in racehorses, and the reported incidence ranges from 0.2 to $13 \%$ [2]. In humans, only a few clinical case reports have been published describing the condition specifically in runners, cyclists, or cross-country skiers [3-5].

\footnotetext{
* Correspondence: ehohmann@houstonmethodist.org

${ }^{1}$ Faculty of Health Sciences, University of Pretoria, Pretoria, South Africa

${ }^{2}$ Department of Orthopaedic Surgery and Sports Medicine, Dubai, United

Arab Emirates

Full list of author information is available at the end of the article
}

Swimming induced pulmonary oedema (SIPE) was first described by Wilmshurst et al. in eleven divers with no demonstrable cardiac abnormality who had up to seven episodes when swimming or scuba diving [6]. The condition would appear to be unusual, with less than 500 cases described in the published literature [7-13]. The condition usually presents with dyspnea, cough, haemoptysis, increased sputum production, wheezing, and chest pain [7-9]. Surprisingly, more than $90 \%$ of athletes have basal inspiratory crackles on routine clinical examination during competition [9].

The pathophysiology of SIPE is not fully understood, but underlying cardiac abnormalities or dysfunction and

(c) The Author(s). 2018 Open Access This article is distributed under the terms of the Creative Commons Attribution 4.0 International License (http://creativecommons.org/licenses/by/4.0/), which permits unrestricted use, distribution, and 
inflammatory processes have been suggested as possible predisposing conditions [12, 14]. During exercise, the transport of oxygen across the alveolar-capillary membrane increases up to five-fold [15]. This is accompanied by an increase in pulmonary arterial and left atrial pressures [1]. In middle-aged and mature athletes these pressures are significantly higher than in healthy normal subjects [16]. Hypoxia contributes to higher pulmonary arterial pressure and further increases the likelihood of pulmonary oedema [17]. Increased pulmonary arterial pressures, combined with dramatically decreased intrathoracic pressures during inspiration, could result in exudation of fluid into the alveoli [1]. With immersion in cold water, redistribution of blood from the extremities to the thorax occurs resulting in increased blood volume in the central veins, further increasing pulmonary arterial systolic pressure [12, 18-20]. In SIPE susceptible athletes, Wilmshurst has suggested that greater vascular resistance in combination with cold water immersion results in an increase in afterload, leading to hydrostatic oedema [6].

The purpose of this systematic review was to summarize the evidence with regards to the prevalence, pathophysiology, and treatment of swimming induced pulmonary oedema in endurance athletes.

\section{Methods}

The research was conducted according to the methods described in the Cochrane Handbook [21]. The results are reported according to the Preferred Reporting Items for Systematic Reviews and Meta-Analysis (PRISMA) guidelines statement [22].

\section{Eligibility criteria}

Published literature was screened for prospective and retrospective level one to level four studies and case reports from 1970 to 2017 reporting on the incidence, pathophysiology, treatment and prevention of swimming induced pulmonary oedema in endurance athletes. Those identified were considered for inclusion if they reported on laboratory based and experimental studies in adult endurance athletes between the age of 18 and 60 with swimming-induced or exercise induced pulmonary oedema. For clinical studies, only publications reporting on swimming-induced pulmonary oedema were considered. Studies were excluded if the study involved scuba divers, military or other professional divers, and case reports and experimental studies investigating the effect of full body immersion simulating diving activities. If studies reported on both swimming and diving induced pulmonary oedema, the abstract and full text was screened and the cases related to swimming extracted. Conference proceedings or abstracts, expert opinions (level V) and review articles were excluded. It is acknowledged that the omission of grey data could potentially result in publication bias, but will also substantially reduce selection bias.

\section{Information sources and literature research}

A systematic review of the literature utilizing Medline, Embase, Scopus and Google Scholar was performed to identify all publications in the English and German literature related to swimming and exercise induced pulmonary oedema. The following search terms and Boolean operators were used: "exercise" AND/OR "swimming" AND/OR "induced" AND/OR "pulmonary oedema"; "endurance athlete" AND/OR "triathlete" AND/OR "pathophysiology"; AND/OR "physiology and pathology". The search was performed on 20 November 2017, and two reviewers independently assessed the titles and abstracts. All eligible articles were then manually cross-referenced to ensure any other potential studies were included. Disagreements were resolved by consensus; if no consensus was achieved a third independent researcher was consulted and the difference resolved by majority vote.

\section{Data extraction and quality assessment}

For studies that met the inclusion criteria, an electronic data extraction form was used to obtain the following information from each article: author, journal and year of publication, any conflicts of interest, water temperature, symptoms, outcomes, and physiological data collected by the authors. Two authors independently completed data extraction, and the third reviewer and senior author verified the data.

Risk of bias for randomized-control level one and two studies was assessed adapting the Cochrane Collaboration's Risk of Bias Tool [21]. Because the Cochrane Handbook does not specifically describe the assessment of risk of bias for observational and laboratory studies, the ROBINS-I tool for the assessment of bias in observational studies was utilized [23]. Briefly, the following domains of bias were considered: due to confounding, selection bias, bias in classification of interventions, bias due to deviations from intended interventions, bias due to missing data, bias related to measurement of outcome, and bias in the selection of the reported results. Each domain of bias is then evaluated with one of the following responses: "yes", "probably yes", "probably no", and "no", with probable responses having similar implications as "yes" or "no". The categories of judgement for each study are low, moderate, serious, and critical risk of bias [23].

The senior author assessed the quality of evidence for each applicable outcome measure using the GRADE system, and the second reviewer verified these assessments [21]. The GRADE assessment defines the quality of 
evidence for observational studies as low, but allows either down- or upgrading based on various factors. Studies were downgraded if limitations in the design, indirectness of evidence, unexplained heterogeneity, imprecision of results, and high probability of publication bias were observed, and study quality was therefore reduced from low to very low. Studies were upgraded if there was a large magnitude of effect, if all plausible confounding would reduce a demonstrated effect or suggest a spurious effect when results showed no effect, and if there was a dose-response gradient observed. All institutional and author information was concealed to the second reviewer to reduce reviewer bias. Any disagreement between reviewers was resolved by consensus, or by arbitration between the two senior authors.

\section{Data synthesis and analysis}

Data pooling and meta-analysis was deemed not possible by the authors because of study heterogeneity, and the fact that none of the included studies were level I or II evidence. A best evidence synthesis, as suggested by Slavin, was therefore utilised [24]. Based on the guidelines for systematic reviews in the Cochrane Collaboration [25], the ranking of the levels of evidence developed by van Meer et al. [26] was used. Strong evidence was defined as two or more studies with low risk of bias, and with $>75 \%$ of the studies reporting consistent finding. Moderate evidence was defined as one low risk of bias study and two or more high risk of bias studies, with consistent findings in more than $75 \%$ of the included studies. Limited evidence was defined as one or more high risk of bias studies or one low risk of bias study, with $>75 \%$ of the studies reporting consistent findings. Conflicting evidence was defined as contradictory findings, with less than $75 \%$ of the studies reporting consistent findings. No evidence was defined if none of the included studies provided any evidence.

\section{Results}

\section{Study selection and characteristics}

The literature search identified 485 studies between the years 1970 and 2017 for consideration. Of these, 284 studies were screened and 214 excluded after reviewing their abstracts. For the remaining 70 studies, examination of

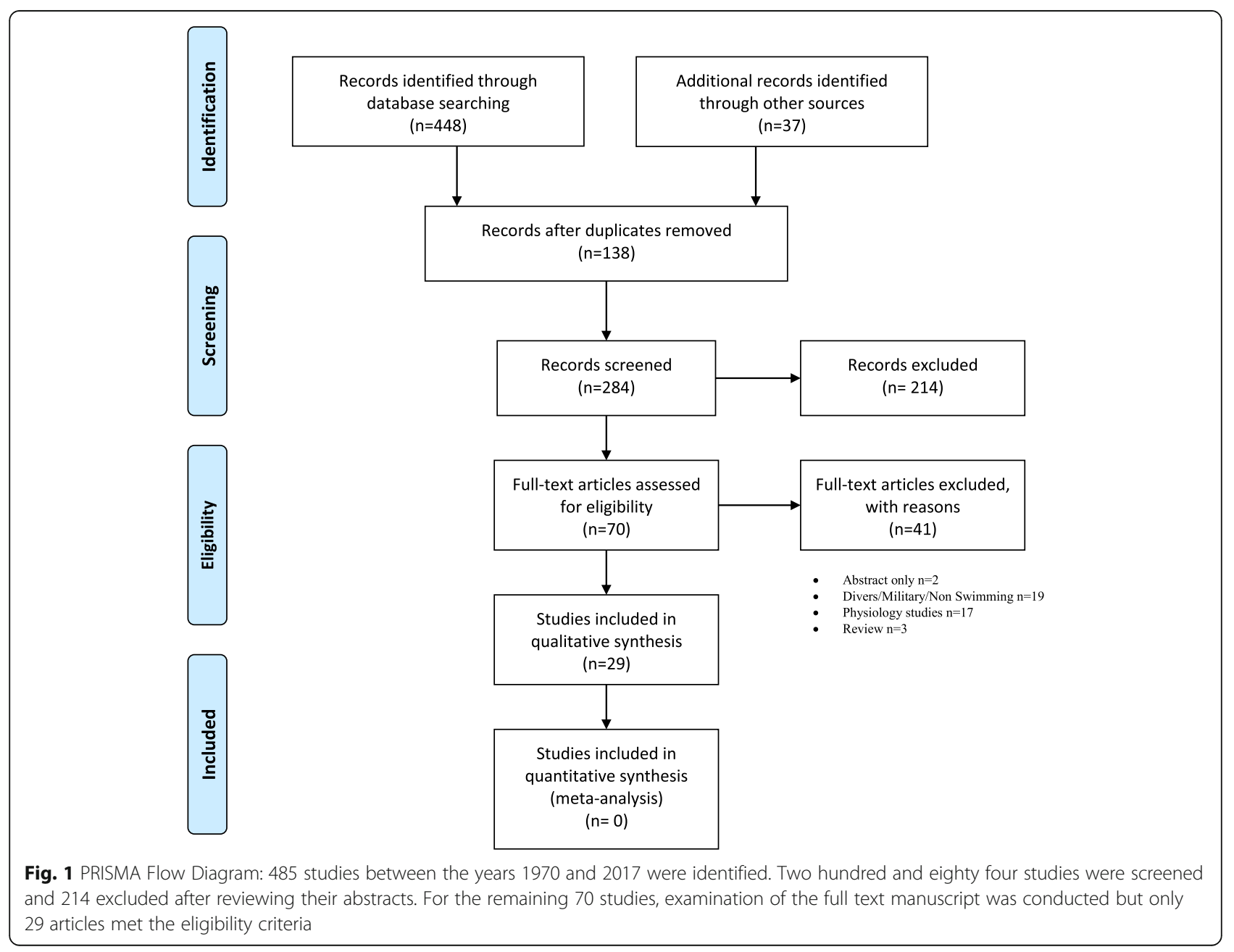


the full text manuscript was conducted. Only 29 articles met the eligibility criteria and were included in the qualitative synthesis (Fig. 1). Nineteen of the 29 studies were case studies $[9,10,12,13,27-41]$. One study described diagnostic techniques [42], while nine articles [7, 8, 14, 18, 43-47] investigated pathophysiology, and one of these studies [7] also suggested treatment options. The study characteristics and results are summarized in Tables 1 and 2 .

\section{Risk of bias}

The findings of the risk assessment for bias are summarized in Tables 3 and 4. None of the eligible studies included randomized clinical trials, and risk of bias for all manuscripts was therefore assessed using the ROBINS-I tool [23]. Nineteen of the 29 included studies were case series $[9,10,12,13,27-41]$, one study described diagnostic techniques [42], nine articles [7, 8, 14, 18, 43-47] investigated pathophysiology, and one study suggested treatment options [7]. Twelve of the 19 case series reporting on prevalence were assessed to have a moderate risk of bias [10, 27-30, 32-36, 38, 39]. Three studies had a serious risk of bias [13, 31, 41]. Four of the studies were considered to have a critical risk of bias $[9,12,37$, 40]. Confounding, selection, intervention, and measurement bias was present in the study by Adir et al. [9]. The authors utilized 70 participants who were enrolled in a swimming program, yet spirometry was only performed in a subgroup of 37 participants [9]. Definite confounding and selection bias, and probable bias for the other five parameters, were found in Ma \&Dutch small case series [37]. SIPE was diagnosed in five triathletes at different stages of the competition, while three athletes required hospital admission [37]. Selection bias and probable classification, missing data, and measurement bias was observed in the case series from Peacher et al. [12]. Volunteers were recruited from a previous physiological study, while the history and SIPE diagnosis was self-reported and the presented data for all identified volunteers was incomplete [12]. Similar to Ma \&

Table 1 Study characteristics and outcomes of the clinical studies

\begin{tabular}{|c|c|c|c|c|c|c|}
\hline & Cases & gender & age & Water temperature & symptoms & outcome \\
\hline Pons 1995 & 4 & & & $18-21^{\circ} \mathrm{C}$ & Dyspnoea (2), cough (4), froth (4) & 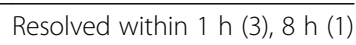 \\
\hline Weiler 1995 & 8 & $M=8$ & 18 & $23^{\circ} \mathrm{C}$ & Cough (7), haemoptysis (8) & Resolved (6) recurring (2) \\
\hline Roeggla 1996 & 1 & $F=1$ & 54 & $14^{\circ} \mathrm{C}$ & Dyspnoea, cough, froth, haemoptysis & Resolved \\
\hline Lund 2003 & 3 & $M=3$ & 24.3 & $19^{\circ} \mathrm{C}$ & $\begin{array}{l}\text { Dyspnoea (3), cough (3), confusion (2), } \\
\text { blurred vision (1), froth (1) }\end{array}$ & Resolved within $48 \mathrm{~h}$ \\
\hline Adir 2004 & 70 & $M=70$ & $18-19$ & $16-22{ }^{\circ} \mathrm{C}$ & $\begin{array}{l}\text { Dyspnoea (70), cough (67), haemoptysis } \\
\text { (39), froth (63), }\end{array}$ & $\begin{array}{l}\text { Resolved within } 24 \mathrm{~h} \text {, } \\
\text { recurrence (16) }\end{array}$ \\
\hline Biswas 2004 & 1 & $M=1$ & 36 & $<22^{\circ} \mathrm{C}$ & Dyspnoea, cough, froth & resolved \\
\hline Shuppak 2004 & 21 & $M=21$ & $18-19$ & $16-18^{\circ} \mathrm{C}$ & Dyspnoea, cough, froth, haemoptysis & Resolved (18), recurring (3) \\
\hline Wilmshurst 2004 & 1 & $M=1$ & 35 & $13^{\circ} \mathrm{C}$ & Dyspnoea, haemoptysis, froth & recurrence \\
\hline Deady 2006 & 1 & $F=1$ & 38 & $15^{\circ} \mathrm{C}$ & Dyspnoea, haemoptysis & Resolved within $24 \mathrm{~h}$ \\
\hline Beinhart 2007 & 1 & $\mathrm{~F}=1$ & 54 & $22^{\circ} \mathrm{C}$ & dyspnoea & resolved \\
\hline Wenger 2007 & 1 & $M=1$ & 43 & $20^{\circ} \mathrm{C}$ & Dyspnoea, froth, chest pain & Resolved within $24 \mathrm{~h}$ \\
\hline Noti 2009 & 1 & $F=1$ & 23 & & Dyspnoea, froth & Resolved within $24 \mathrm{~h}$ \\
\hline Carter 2011 & 3 & $F=3$ & 49.7 & $15-19{ }^{\circ} \mathrm{C}$ & $\begin{array}{l}\text { Dyspnoea (3), froth (2), cough (1), } \\
\text { haemoptysis (1), chest pain ( } 2 \text { ) }\end{array}$ & Resolved (1), Recurrence (1) \\
\hline Ma 2013 & 5 & $M=5$ & 42.6 & $<22^{\circ} \mathrm{C}$ & $\begin{array}{l}\text { Dyspnoea (3), cough (2), Haempotysis } \\
\text { (3), froth (1) }\end{array}$ & Resolved within 1 week \\
\hline North 2013 & 1 & $F=1$ & 26 & $<22^{\circ} \mathrm{C}$ & Dyspnoea, cough, froth & Resolved within $48 \mathrm{~h}$ \\
\hline Casey 2014 & 2 & $M=1, f=1$ & 57.5 & $<22^{\circ} \mathrm{C}$ & $\begin{array}{l}\text { Dyspnoea (2), froth (1), cough (1), chest } \\
\text { pain (1) }\end{array}$ & Resolved within $24 \mathrm{~h}$ \\
\hline Peacher 2015 & 41 & & 50.1 & & & \\
\hline Yamamashi 2015 & 5 & $M=1$ & 41.8 & $21^{\circ} \mathrm{C}$ & Dyspnoea (5), haemoptysis (1), cough (1) & Resolved within 10 days \\
\hline Beale 2016 & 4 & $M=4$ & 36.7 & & $\begin{array}{l}\text { Dyspnoea (4), cough (3), haemoptysis (2), } \\
\text { froth (3) }\end{array}$ & Resolved (4), recurrence (2) \\
\hline$N=20$ & 174 & $M=165 F=9$ & & $13-22{ }^{\circ} \mathrm{C}$ & $\begin{array}{l}\text { Dyspnoea (90), cough (97), froth (89), } \\
\text { haemoptysis (58), blurred vision (1), } \\
\text { chest pain (3) }\end{array}$ & Resolved (185), recurrence (25) \\
\hline
\end{tabular}


Table 2 Study characteristics and outcomes of the clinical studies

\begin{tabular}{|c|c|c|c|c|}
\hline $\begin{array}{l}\text { Caillaud } \\
1995\end{array}$ & Pulmonary function & $\begin{array}{l}\mathrm{DL}_{\mathrm{CO},} \mathrm{K}_{\mathrm{CO}}, V_{\mathrm{A}}, \text { Pulmonary } \\
\text { Volume (CT), MLD }\end{array}$ & $\begin{array}{l}\text { Pre- and post Olympic } \\
\text { Triathlon } \\
\text { Water temperature } 14{ }^{\circ} \mathrm{C}\end{array}$ & $\begin{array}{l}\text { No change in VC and TLC, DLCO } \\
\text { and KCO reduced, slight increase in } \\
\text { extrapulmonary water, significant } \\
\text { increase in MLD }\end{array}$ \\
\hline $\begin{array}{l}\text { Choi } \\
2004\end{array}$ & $\begin{array}{l}\text { Arrythmia Long QT } \\
\text { syndrome }\end{array}$ & & Genetic testing & $\begin{array}{l}\text { LQTS +CPVT1 gene present in 90.7\% } \\
\text { swimming triggered events }\end{array}$ \\
\hline $\begin{array}{l}\text { Ludwig } \\
2006\end{array}$ & Pulmonary function & $\mathrm{TLC}, \mathrm{VC}, \mathrm{FEV}_{1}, \mathrm{FEV}_{1} / \mathrm{FVC}, \mathrm{DL}_{\mathrm{CO}}$ & $\begin{array}{l}\text { Non randomized study, testing } \\
\text { following cycle ergometry, SIPE } \\
\text { subjects versus control group }\end{array}$ & No difference between groups \\
\hline $\begin{array}{l}\text { Wester } \\
2009\end{array}$ & Pulmonary function & $\begin{array}{l}V T, V_{\mathrm{O} 2}, V_{E}, V D N T, V_{\mathrm{CO} 2}, P_{1}, P_{\mathrm{CO} 2} \\
P_{\mathrm{O} 2}, \mathrm{MAP}, \mathrm{MPAP}, \mathrm{PAWP}, \mathrm{CVP}\end{array}$ & $\begin{array}{l}\text { Dry and immersion exercise in } \\
\text { cold }\left(19^{\circ} \mathrm{C}\right) \text { and warm }\left(28^{\circ} \mathrm{C}\right)\end{array}$ & MPAP, CVP higher in cold water \\
\hline $\begin{array}{l}\text { Fraser } \\
2010\end{array}$ & Pulmonary function & $\begin{array}{l}\text { VC, FEV } 1, \mathrm{FEV}_{25-75,} \mathrm{HCVR} \mathrm{VO}_{2 \text { max }} \\
\text { PAP, MAP, MPAP, CVP }\end{array}$ & $\begin{array}{l}\text { Cold water immersions } \\
\left(20-21^{\circ} \mathrm{C}\right) \\
\text { Hyper vs normoxia }\end{array}$ & $\begin{array}{l}\text { Cold water immersion associated with } \\
\text { higher mean PAP, PVR, MPAP favouring } \\
\text { conditions for pulmonary oedema, PAWP } \\
\text { approached threshold to pulmonary } \\
\text { capillary leak pressures }\end{array}$ \\
\hline $\begin{array}{l}\text { Harris } \\
2010\end{array}$ & Deaths in Triathlons & Heart Morphology & Autopsy $(n=9)$ & $\begin{array}{l}7 \text { left } \mathrm{VH}, 1 \text { congenital coronary artery } \\
\text { anomaly }\end{array}$ \\
\hline $\begin{array}{l}\text { Pingitore } \\
2011\end{array}$ & $\begin{array}{l}\text { Echocardiography, Chest } \\
\text { Ultrasound, Pulmonary } \\
\text { function }\end{array}$ & $\begin{array}{l}\text { VC, FEV1, Troponin, IL } \\
\text { LV systolic function and } \\
\text { volume }\end{array}$ & Pre- and post Ironman event & $\begin{array}{l}\text { Transient and interstitial pulmonary } \\
\text { oedema in all athletes }\end{array}$ \\
\hline $\begin{array}{l}\text { Moon } \\
2016\end{array}$ & Deaths in Triathlons & $\begin{array}{l}\text { Heart mass, ventricular } \\
\text { thickness, coronary } \\
\text { abnormalities }\end{array}$ & Autopsy $(n=23)$ & $\begin{array}{l}\text { 95\% heart mass > than normal, } \\
23>70 \% \text { CAD narrowing, 32\%> } \\
\text { 50\%CAD narrowing }\end{array}$ \\
\hline $\begin{array}{l}\text { Moon } \\
2016\end{array}$ & Pulmonary function & CVP, MAP, MPAP, PAWP & Submersion in $20^{\circ} \mathrm{C}$ water & $\begin{array}{l}\text { CVP } 23 \% \text { increase, PAWP } 25 \% \text { increase, } \\
\text { MPAP } 26 \% \text { increase, MAP } 7 \% \text { increase }\end{array}$ \\
\hline $\begin{array}{l}\text { Shearer } \\
2009\end{array}$ & $\begin{array}{l}\text { Brain natriuretic } \\
\text { peptide (BNP) }\end{array}$ & BNP & $\begin{array}{l}\text { BNP levels in } 6 \text { cases } \\
\text { confirmed with SIPE in the ER }\end{array}$ & Within normal for all subjects \\
\hline
\end{tabular}

Dutch [37], Yamamashi et al. [40] have reported on six athletes with a diagnosis of SIPE during a triathlon, and bias was present for all seven items.

Four of the studies reporting on pathophysiology had a moderate risk of bias [18, 43, 45, 47], three studies a serious risk of bias $[8,14,46]$, and one study [44] a critical risk of bias. Probable confounding, selection, missing data, and reporting bias were determined to be present in the study by Choi et al. [44]. They performed genetic testing for long QT syndrome in 388 unrelated patients, and also evaluated the family history by review of medical records or phone interview. A specific gene was identified in only two thirds of swimming related cases. Shearer and Mahon [42] reported on the value of brain natriuretic peptide (BNP) to diagnose SIPE, but only six cases were tested and no conclusion could be drawn. The risk of bias in this study was assessed as serious [42]. There was only one publication discussing treatment options, by Moon et al., who reported on the benefits of sildenafil in athletes with a history of SIPE [7]. Utilizing radial artery and pulmonary artery catheters in 10 volunteers performing immersion cycle ergometry, significant differences between SIPE susceptible subjects and a control group were observed. Although these differences were not observed following administration of $50 \mathrm{mg}$ Sildenafil, the risk of bias was assessed as moderate.

Utilizing the GRADE quality scheme, none of the included studies were upgraded. Of the 19 prevalence and case series studies, ten were downgraded to very low quality because of limitations in the design and imprecision $[9,10,12,13,27,28,31,37,40,41]$. Of the ten studies investigating pathophysiology, three were downgraded to very low quality based on design limitations $[7,14,42,44]$.

\section{Prevalence}

The prevalence of SIPE in humans is not clear and possibly underreported. Pons et al. reported a prevalence of $1.1 \%$ in a mixed cohort of swimmers and divers, and Miller et al. estimated a population prevalence of $1.4 \%$ in triathletes $[27,48]$. A prevalence of $1.8 \%$ has been reported previously in combat military swimmers [9]. The pooled data here from the 19 included studies reported a total of 174 athletes; 165 were males and 9 were females (Table 1$)$. The most common symptom was cough $(n=97)$, dyspnoea $(n=90)$, froth $(89)$ and haemoptysis $(n=58)$. Uncommon symptoms included chest pain $(n=$ 3) and blurred vision. Chest pain was only reported by athletes older than 40 years. In all but 5 athletes 
Table 3 Risk assessment for bias for the clinical studies

\begin{tabular}{|c|c|c|c|c|c|c|c|c|}
\hline & $\begin{array}{l}\text { Confounding } \\
\text { Bias }\end{array}$ & $\begin{array}{l}\text { Selection } \\
\text { Bias }\end{array}$ & $\begin{array}{l}\text { Classification } \\
\text { Bias }\end{array}$ & $\begin{array}{l}\text { Intervention } \\
\text { Bias }\end{array}$ & $\begin{array}{l}\text { Missing Data } \\
\text { Bias }\end{array}$ & $\begin{array}{l}\text { Measurement } \\
\text { Bias }\end{array}$ & $\begin{array}{l}\text { Reporting } \\
\text { Bias }\end{array}$ & Bias \\
\hline Pons 1995 & $n$ & py & pn & pn & $n$ & py & $n$ & moderate \\
\hline Weiler 1995 & py & py & $n$ & $n$ & $n$ & $n$ & $n$ & moderate \\
\hline Roeggla 1996 & $n$ & $n$ & $n$ & $n$ & $n$ & $n$ & $n$ & moderate \\
\hline Lund 2003 & pn & py & $\mathrm{n}$ & $n$ & $n$ & py & pn & moderate \\
\hline Adir 2004 & y & y & $n$ & y & $n$ & $y$ & pn & critical \\
\hline Biswas 2004 & $n$ & $n$ & $n$ & $n$ & $n$ & $n$ & $n$ & moderate \\
\hline Shuppak 2004 & y & y & $\mathrm{n}$ & $\mathrm{n}$ & $n$ & py & py & serious \\
\hline $\begin{array}{l}\text { Wilmshurst } \\
2004\end{array}$ & $n$ & y & $\mathrm{n}$ & $\mathrm{n}$ & y & $n$ & $n$ & serious \\
\hline Deady 2006 & $n$ & $n$ & $n$ & $n$ & $n$ & $n$ & $n$ & moderate \\
\hline Beinhart 2007 & $n$ & $n$ & $n$ & $n$ & $n$ & $n$ & $n$ & moderate \\
\hline Wenger 2007 & $n$ & $n$ & $n$ & $n$ & $n$ & $n$ & $n$ & moderate \\
\hline Noti 2009 & $n$ & $n$ & $n$ & $n$ & $n$ & $n$ & $n$ & moderate \\
\hline Carter 2011 & $n$ & $n$ & $n$ & $n$ & $n$ & $n$ & $n$ & moderate \\
\hline Ma 2013 & $\mathrm{n}$ & py & py & pn & $n$ & y & py & critical \\
\hline North 2013 & $n$ & $n$ & $n$ & $n$ & py & py & $n$ & moderate \\
\hline Casey 2014 & $n$ & $\mathrm{n}$ & $n$ & $n$ & $n$ & $n$ & $n$ & moderate \\
\hline Peacher 2015 & $\mathrm{pn}$ & y & py & $n$ & py & py & pn & critical \\
\hline $\begin{array}{l}\text { Yamamashi } \\
2015\end{array}$ & y & y & py & py & py & py & py & critical \\
\hline Beale 2016 & $n$ & y & pn & py & pn & py & $\mathrm{pn}$ & serious \\
\hline North 2013 & & & & & & & & \\
\hline
\end{tabular}

symptoms resolved within $48 \mathrm{~h}$ [40]. Recurrence of SIPE was reported in 25 athletes (14.4\%). Reported risk factors included asthma $(n=2)$, environmental allergies $(n=2)$, hypertension $(n=1)$, previous pneumonia $(n=1)$, type 1 diabetes mellitus $(n=1)$, and a history of smoking $(n=$ 1). The water temperature was lower than $23{ }^{\circ} \mathrm{C}$ in all cases and ranged from 13 to 23 degrees Celsius. The best evidence-based analysis suggests that there was moderate indication for an association between water temperature and the prevalence of SIPE. The water temperature resulting in SIPE in the included clinical studies ranged from 13 [31] to 23 degrees Celsius [28]. In the studies investigating pathophysiological variables the temperatures ranged from 14 [43] to 21 degrees Celsius [45].

Further best evidence analysis demonstrated that the presence of the clinical symptoms of cough, dyspnoea, froth, and haemoptysis are all strongly associated with SIPE in athletes during or immediately following swimming events or during the swimming leg during triathlons. There is limited evidence to suggest that there are pre-existing risk factors leading to SIPE with exposure to strenuous physical activity during swimming.

\section{Pathophysiology}

Of the eight studies included here, six investigated pulmonary function in swimmers and triathletes $[7,14,18$, $43,45,47]$, two investigated deaths in triathlons $[8,46]$, and one was related to cardiac factors [47]. Cold water swimming resulted in an increase in CVP, MPAP, mean PVR, and PAWP. A significant reduction in DLCO and KCO was noticed by Caillaud et al. [43], which was associated with a significant increase in MLD and an increase in extra-pulmonary water. Pingitore et al. reported transient interstitial pulmonary oedema in all athletes diagnosed with SIPE [47]. In contrast, Ludwig et al. could not demonstrate any differences in pulmonary function parameters between a group of athletes with SIPE and a control group without [14]. Cardiac abnormalities were found in more than $90 \%$ of deaths related to the triathlon swim leg $[8,46]$. Harris reported that 7/9 athletes had left ventricular hypertrophy, and 1/9 a congenital coronary artery anomaly [46]. Moon demonstrated that $95 \%$ had a larger heart mass than normal, $23 \%$ showed coronary artery stenosis of $>70 \%$, and $32 \%$ showed coronary artery stenosis of $>50 \%$. (Table 2) [8].

The only study investigating cardiac parameters reported significant decreases of LV end-diastolic volumes, 
Table 4 Risk assessment for bias the basic science studies

\begin{tabular}{|c|c|c|c|c|c|c|c|c|}
\hline & $\begin{array}{l}\text { Confounding } \\
\text { Bias }\end{array}$ & $\begin{array}{l}\text { Selection } \\
\text { Bias }\end{array}$ & $\begin{array}{l}\text { Classification } \\
\text { Bias }\end{array}$ & $\begin{array}{l}\text { Intervention } \\
\text { Bias }\end{array}$ & $\begin{array}{l}\text { Missing Data } \\
\text { Bias }\end{array}$ & $\begin{array}{l}\text { Measurement } \\
\text { Bias }\end{array}$ & $\begin{array}{l}\text { Reporting } \\
\text { Bias }\end{array}$ & Bias \\
\hline \multicolumn{9}{|c|}{ Pathophysiology } \\
\hline 1995 Caillard & $n$ & $n$ & $n$ & $n$ & $n$ & $n$ & $n$ & moderate \\
\hline 2004 Choi & py & py & pn & pn & py & $n$ & py & critical \\
\hline 2006 Ludwig & py & py & $n$ & $n$ & $n$ & $n$ & $n$ & serious \\
\hline 2009 Wester & $n$ & $n$ & $n$ & $n$ & $n$ & $n$ & $n$ & moderate \\
\hline 2010 Harris & $n$ & py & $n$ & $n$ & y & $n$ & py & serious \\
\hline 2010 Fraser & $n$ & $n$ & $n$ & $n$ & $n$ & $n$ & $n$ & moderate \\
\hline 2011 Pingitore & $\mathrm{n}$ & $n$ & $n$ & $n$ & $n$ & $n$ & $n$ & moderate \\
\hline 2016 Moon & y & y & $n$ & $n$ & $\mathrm{n}$ & $n$ & $n$ & serious \\
\hline \multicolumn{9}{|l|}{ DX } \\
\hline 2009 Shearer & y & py & pn & pn & $\mathrm{pn}$ & $n$ & $n$ & serious \\
\hline \multicolumn{9}{|l|}{$R X$} \\
\hline 2016.1 Moon & $n$ & $n$ & $\mathrm{n}$ & $n$ & $\mathrm{n}$ & $\mathrm{n}$ & $\mathrm{n}$ & moderate \\
\hline
\end{tabular}

significant decreases in the ejection fraction from 72 to $66 \%$, a decrease in right heart function, and significant increases in cardiac troponin from 0.02 to $0.14 \mathrm{ng} / \mathrm{ml}$ following an Ironman race [47], while also demonstrating significant increases in BNP. They concluded these exercise induced haemodynamic changes were the cause of the transient and asymptomatic exercise induced interstitial pulmonary oedema observed in all 31 athletes included in their study [47].

Best evidence analysis suggests there was strong evidence that cold water immersion results in increases for CVP, MPAP, PVR and PAWP, leading to an increase in asymptomatic interstitial oedema. There is also strong post-mortem evidence from triathletes having died during events that pathological findings are often associated with coronary artery stenosis and left ventricular hypertrophy.

\section{Discussion}

The results of this best evidence analysis suggest that swimming in cold water is one of the potential triggers for SIPE. Cold water immersion increases CVP, MPAP, PVR and PAWP, providing a possible explanation why individuals become susceptible to interstitial pulmonary oedema. The reported water temperature in the included studies investigating cold water induced SIPE ranged from 13 to 23 degrees. Based on these reports, cold water could therefore be defined as a water temperature of less than 23 degrees Celsius. The index of suspicion for SIPE should be high when athletes present with cough, dyspnoea, froth, and haemoptysis. Best evidence analysis could not identify specific risk factors leading to pulmonary oedema with exposure to swimming in cold water.
Currently there is no evidence as to why certain individuals are susceptible to SIPE. Miller et al. conducted a review of the 104,887 Triathlon USA members via an online survey [48]. They reported a prevalence of $1.4 \%$, indicating that very few athletes are affected. However, the validity of their findings are severely limited as only 1400 members responded to the survey. For this study, the definition of SIPE was limited to a single variable: 'cough productive of pink frothy or blood-tinged secretions'. In addition to the very low response rate, it is highly likely that milder cases of SIPE were missed in this survey. In a small comparative study, Moon et al. suggested that an exaggerated increase in MPAP and PAWP could be a possible aetiology for SIPE [7]. In subjects with a confirmed history of SIPE, the authors demonstrated lower baseline oxygen consumption, heart rates, stroke volumes, and cardiac output [7].

Earlier, Caillaud et al. used CT scanning in eight male athletes to measure water accumulation in the lungs before and after a triathlon [43]. They demonstrated an increased mean lung density following the race, suggesting interstitial fluid accumulation. McKenzie et al. used MR imaging to investigate SIPE, and showed a 9.4\% increase in pulmonary extravascular water [49]. Miles et al. described a significant increase in alveolar-capillary membrane resistance that was associated with a decrease in DLCO and DM and remaining vital capacity after a marathon race [50]. They interpreted these findings as the presence of subclinical pulmonary oedema. Six studies investigated pulmonary function in swimmers and triathletes $[7,14,18,43,45,47]$. They reported cold-water swimming resulted in an increase in CVP, MPAP, mean PVR, and PAWP, and also a significant reduction in DLCO and KCO [7, 14, 18, 43, 45, 47]. 
Unfortunately, none of these authors differentiated between the potential causes and consequences of SIPE. Increases in PAP, PVR and PAWP are the likely causes of SIPE, whereas reductions in DLCO and $\mathrm{KCO}$ as a result of secondary increased resistance at the alveolar-capillary interface are likely consequences of SIPE. Similar to SIPE, high altitude pulmonary oedema (HAPE) may have very similar pathophysiological changes. Eldridge et al. investigated the effect of high altitude on pulmonary blood flow and alveolar leakage in eight endurance athletes [51] Using cycle ergometry with $90 \%$ maximal effort, all athletes developed permeability oedema even at normal altitude. Increased altitude resulted in significantly higher fluid leakage into the alveolar space, a typical pathophysiological response to exercise under hypobaric conditions. Cold water immersion and the physiological responses to race conditions such as nervousness, anxiety, and excitement may trigger exaggerated sympathetic responses, resulting in SIPE in susceptible individuals [52, 53].

However, the hypothesis of exercise induced interstitial oedema is controversial, and other researchers have shown that exercise does not result in pulmonary oedema [54, 55]. Similar to Cailleaud et al. [43], Manier et al. [55] examined lung density using CT scans. In nine trained endurance runners before and after a $2 \mathrm{~h}$ treadmill run, they could not demonstrate any significant post exercise changes in lung mass or density. Hodges et al. examined extravascular lung water in 10 male subjects undergoing $60 \mathrm{~min}$ of cycling in both hypoxic and normoxic conditions [54]. They could not demonstrate any evidence of post-exercise pulmonary oedema under either condition.

Whilst best evidence analysis could not identify specific risk factors, Peacher et al. reported that of the 36 athletes with immersion pulmonary oedema, 24 (67\%) had pre-existing cardiac or pulmonary abnormalities, compared to only $45 \%$ in a historical control group [12]. These abnormalities included hypertension, left ventricular hypertrophy, cardiomegaly, chronic atrial fibrillation, coronary artery disease, asthma, and exercise induced cough [12]. However, the validity of their findings is severely limited due to incomplete medical records and historical controls. Furthermore, the authors included divers, introducing further selection bias. In a case-control group, Miller et al. compared 1411 athletes with SIPE to a group of 31 healthy control subjects. Advanced age (OR 3.35), hypertension (OR 4.87), diabetes (OR 7.63), fish oil use (OR 3.1), and a long course (OR 3.32) were all associated with higher risk [48]. The value of this study is again limited by the low response rate, the retrospective survey design, and the self-reported diagnoses.
Swimming is one of the three disciplines during a triathlon, and respiratory symptoms are most often reported during the swim leg [7, 8]. Moon et al. and Harris et al. investigated the causes of death during the triathlon swim leg $[8,46]$. SIPE was reported to be the most likely cause, and the reasons for pulmonary oedema in these athletes was explained by the presence of left ventricular hypertrophy, lusitropy, abnormal conduction, and coronary artery stenosis exceeding 50\% resulting in possible abnormal LV diastolic compliance $[8,46]$. Moon et al. reported that the majority of athletes who died had left ventricular hypertrophy [46]. However, these findings could also be related to normal physiological changes in endurance athletes. Douglas et al. determined that left ventricular wall thickness of more than $13 \mathrm{~mm}$ in athletes represents a pathological condition [56]. Moon reported the mean LV thickness in his series exceeded these values by two millimetres, and the observed hypertrophy was therefore most likely pathological $[7,8]$. In addition, the presence of $>70 \%$ coronary artery stenosis was noted in $23 \%$,of athletes, and $>50 \%$ in $32 \%$ of athletes, suggesting asymptomatic coronary disease may be a contributing factor $[7,8]$.

Harris reported one case (7\%) with WolffParkinson-White syndrome and two (14\%) with a structurally abnormal heart [46]. Whether arrhythmias has contributed to death in these two cases cannot reliably be established but the combination of abnormal heart morphology, physiological stress reactions, and cold water immersion could certainly cause arrhythmias resulting in sudden death. Claessens et al. has demonstrated a significantly higher rate of premature ventricular beats in triathletes [57]. These findings are supported by Fuchs et al., who demonstrated athletes engaged in competitive sports develop ventricular arrhythmias during exercise [58]. Shattock and Tipton proposed autonomic conflict as a possible cause of cardiac arrhythmias during cold water submersion [53]. The activation of a sympathetic system-driven tachycardia with cold water submersion and breath holding promoting a parasympathetic system-driven bradycardia may cause arrhythmias, which can cause sudden death in vulnerable individuals [53]. Warburton et al. used signal-averaged electrocardiography (SAECG) to determine late potentials (LP) [59]. They suggested the presence of LPs may indicate that prolonged, strenuous exercise could result in electrical instability triggering arrhythmias [59].

Best evidence analysis suggested that the evidence was strong to support the association of death and cardiac pathology. The results of this study therefore strongly suggest pre-screening for middle-aged triathlon or endurance athletes as a preventative risk reduction measure. In addition, recommendations to reduce the size of the starting groups, larger wave intervals, rolling starts, 
allowing pre-swims to adjust to the water temperature, and well planned emergency action plans may improve swim safety [52].

Best evidence synthesis allows detailed analysis of study flaws and study characteristics when data pooling and meta-analysis is not possible. The limitations of this study are inherent to the limitations of the included studies. Seven of the 19 clinical studies had serious and critical risk of bias, and ten were downgraded with regard to study quality. Of the ten studies investigating pathophysiology, four were found to have serious and critical risk of bias, and these four studies were downgraded to very low quality. The low quality of the included studies limits both internal and external validity. It could be argued that the results of this study should therefore be viewed with caution. However, despite moderate evidence for the association between cold water immersion and the prevalence of SIPE, the findings of all 19 studies are consistent, strengthening the conclusions. Given the limited evidence between SIPE and pre-existing risk factors, further studies are needed and the evidence here must be viewed with caution. Exercise physiology and pathophysiological responses may differ between different races and people with differing ethnic origins. Of the 29 studies included in this systematic review, 28 were performed in Western countries, with populations of predominantly Caucasian origin. It is possible that the majority of the included patients were therefore also of Caucasian descent, introducing minor selection bias. However, almost all of these studies were based in the United Kingdom, USA, Canada, or Australia. These societies are all multicultural and there is a distinct possibility that individuals from a different genetic heritage were also included, although it is not possible to determine how this may, or may not, have influenced the results. Wet-bulb temperature was not reported in the included studies, although wet-bulb temperature may better reflect an individual's perception of water temperature. However, there is no current evidence to support this possibility, and the available literature does not allow further comment regarding any potential relationship between conditions in the water and the ambient environment.

\section{Conclusion}

The results of this best evidence systematic review suggest a moderate association between water temperature and the prevalence of SIPE. The presence of specific clinical symptoms including cough, dyspnoea, froth, and haemoptysis are strongly suggestive of SIPE during or immediately following swimming. There is only limited evidence to suggest that there are pre-existing risk factors leading to SIPE with exposure to strenuous physical activity during swimming. There is strong evidence that sudden deaths of triathletes are often associated with cardiac abnormalities.

\section{Abbreviations \\ CT: Computer tomogram; CVP: Central venous pressure; DLCO: Carbon Monoxide Diffusing Capacity; KCO: Lung transfer coefficient; MLD: Mean lung dose; MPAP: Mean pulmonary arterial pressure; PAWP: Pulmonary arterial wedge pressure; PVR: Peripheral vascular resistance; SIPE: Swimming induced pulmonary oedema}

\section{Acknowledgements}

Not applicable.

Funding

Not applicable.

\section{Availability of data and materials}

The datasets used and/or analysed during the current study are available from the corresponding author on reasonable request.

\section{Authors' contributions}

All authors have contributed to the manuscript and had full access to all the data and take responsibility for the integrity of the data and the accuracy of the data analysis. EH, VG and KT contributed equally. Study conception and design: $E H, K T$, acquisition of data: $E H, K T$; analysis and interpretation of data: $E H, V G, K T$; drafting of manuscript: EH, VG, KT; critical revision and final approvement: EH, VG, KT. All authors read and approved the final manuscript.

\section{Ethics approval and consent to participate}

All procedures performed in this study in regard to the human participants were in accordance with the ethical standards of the institutional and/or national research committee and with the 1964 Helsinki declaration and its later amendments or comparable ethical standards.

\section{Consent for publication}

Not applicable

\section{Competing interests}

The authors declare that they have no competing interests.

\section{Publisher's Note}

Springer Nature remains neutral with regard to jurisdictional claims in published maps and institutional affiliations.

\section{Author details}

${ }^{1}$ Faculty of Health Sciences, University of Pretoria, Pretoria, South Africa. ${ }^{2}$ Department of Orthopaedic Surgery and Sports Medicine, Dubai, United Arab Emirates. ${ }^{3}$ Valiant Clinic/Houston Methodist Group, PO Box 414296, City Walk, 13th street, Dubai, United Arab Emirates. ${ }^{4}$ University of Texas Health Science Center, San Antonio, TX, USA. 'Department of Orthopaedic Surgery, Royal Brisbane Hospital, Herston, Australia. ${ }^{6}$ Department of Surgery, School of Medicine, University of Queensland, Brisbane, Australia. ${ }^{7}$ Orthopaedic Research Institute of Australia, Queensland University of Technology, Brisbane, Australia.

Received: 21 April 2018 Accepted: 23 October 2018

Published online: 01 November 2018

\section{References}

1. Bates ML, Farell ET, Eldridge MW. The curious question of exercise-induced pulmonary edema. Pulm Med. 2011:361931. https://doi.org/10.1155/2011/ 361931.

2. Birks EK, Durando MM, McBride S. Exercise-induced pulmonary haemorrhage. Vet Clin Equine. 2003;19:87-100.

3. Luks AM, Robertson HT, Swenson ER. An ultracyclist with pulmonary edema during the bicycle race across America. Med Science Sports Exerc. 2007; 39(1):8-12.

4. Ghio AJ, Bassett M. Exercise-induced pulmonary haemorrhage after running a marathon. Lung. 2006;184(6):331-3. 
5. McKechnie JK, Leary WP, Noakes TD. Acute pulmonary oedema in two athletes during a 90-km running race. South Afr Med J. 1979;56(7):261-5.

6. Wilmshurst PT, Nuri M, Crowther A, et al. Cold induced pulmonary oedema in scuba divers and swimmers and subsequent development of hypertension. Lancet. 1989;1(8629):62-5.

7. Moon RE, Martina SD, Peacher DF, et al. Swimming-induced pulmonary edema. Pathophysiology and risk reduction with sildenafil. Circulation. 2016; 133:988-96.

8. Moon RE, Martina SD, Peacher DF, et al. Death in triathletes: immersion pulmonary oedema as a possible cause. BMJ Open Sports Exerc Med. 2016; 2:e000146.

9. Adir J, Shupak A, Gil A, et al. Swimming-induced pulmonary edema: clinical presentation and serial lung function. Chest. 2004;126:394-9.

10. Lund KL, Mahon RT, Tanen DA, et al. Swimming-induced pulmonary edema. Ann Emerg Med. 2003;41:251-6.

11. Mahon RT, Kerr S, Amundson D, et al. Immersion pulmonary edema in special forces combat swimmers. Chest. 2002;122:383-4.

12. Peacher DF, Martina SD, Otteni CE, et al. Immersion pulmonary edema and comorbidities: case series and updated review. Med Sci Sports Exerc. 2015; 47:1128-34.

13. Shupak A, Weiler-Ravell D, Adir Y, et al. Pulmonary oedema induced by strenuous swimming: a field study. Respir Physiol. 2000;121:25-31.

14. Ludwig BB, Mahon RT, Schwartzman EL. Cardiopulmonary function after recovery from swimming-induced pulmonary edema. Clin J Sport Med. 2006;16:348-51.

15. Hermansen L, Ekblom B, Saltin B. Cardiac output during submaximal and maximal treadmill and bicycle exercise. J Appl Physiol. 1970;29(1):82-6.

16. Kovacs G, Berghold A, Scheidl S, et al. Pulmonary arterial pressure during rest and exercise in healthy subjects: a systematic review. Eur Respir J. 2009; 34(4):888-94.

17. Naeije R, Chesler N. Pulmonary circulation at exercise. Compr Physiol. 2014; 2(1):711-41.

18. Wester TE, Cherry AD, Pollock NW, et al. Effects of head and body cooling on hemodynamics during immersed prone exercise at 1 ATA. J Appl Physiol (1985). 2009;106:691-700.

19. Lange $L$, Lange $S$, Echt $M$, et al. Heart volume in relation to body posture and immersion in a thermo-neutral bath. A roentgenometric study. Pflugers Arch. 1974;352:219-26.

20. Begin R, Epstein M, Sackner M, et al. Effects of water immersion to the neck on pulmonary circulation and tissue volume in man. J Appl Physiol. 1976; 40(3):293-9.

21. Higgins JPT, Green S. Cochrane handbook for systematic reviews of interventions. Version 5.1.9 [updated March 2011]. The Cochrane Collaboration. 2011.

22. Moher D, Liberati A, Tetzlaff J, et al. Preferred reporting items for systematic reviews and meta-analysis: the PRISMA statement. Int J Surg. 2010;8:336-4.

23. Sterne JA, Hernan MA, Reeves BC, et al. ROBINS-l: a tool for assessing risk of bias in non-randomised studies of interventions. BMJ. 2016;14919:355.

24. Slavin RE. Best evidence synthesis: an intelligent alternative to meta-analysis. J Clin Epidemiol. 1995;48(1):9-18

25. Van Tulder M, Furlan A, Bombardier C, et al. Updated method guidelines for systematic reviews in the Cochrane collaboration back review group. Spine. 2003:28(12):1290-9.

26. Van Meer BL, Meuffels DE, van Eijsden WA, et al. Which determinants predict tibiofemoral and patellofemoral osteoarthritis after anterior cruciate ligament injury? A systematic review. Br J Sports Med. 2015;49(15):975-83.

27. Pons M, Blickenstorfer D, Oechslin E, et al. Pulmonary oedema in healthy persons during scuba-diving and swimming. Eur Respir J. 1995;8:762-7.

28. Weiler-Ravell D, Shupak A, Goldenberg I, et al. Pulmonary oedema and haemoptysis induced by strenuous swimming. BMJ. 1995;311:361-2

29. Roeggla M, Roeggla G, Seidler D, et al. Self-limiting edema with alveolar haemorrhage during diving in cold water. Am J Emerg Med. 1996;14(3):333.

30. Biswas R, Shibu PK, James CM. Pulmonary oedema precipitated by cold water swimming. Br J Sports Med. 2004:38:e36.

31. Wilmshurst PT. Pulmonary oedema induced by emotional stress, by sexual intercourse and by exertion in a cold environment in people without evidence of heart disease. Heart. 2004;90:806-7.

32. Deady B, Glezos J, Blackie S. A swimmer's wheeze. Can J Emerg Med. 2006 8(4):281.

33. Beinhard R, Matetzky S, Arad T, et al. Cold water-induced pulmonary edema. Am J Med. 2007;120:e3.
34. Wenger M, Russi EW. Aqua jogging-induced pulmonary oedema. Eur Respir 2007:30:1231-2

35. Noti F, Helbling A, Allemann Y. Swimming-induced pulmonary oedema. Schweiz Med Forum. 2009:9(8):174-6.

36. Carter EA, Koehle MS. Immersion pulmonary edema in female triathletes. Pulm Med. 2011:2011:261404.

37. Ma JLG, Dutch MJ. Extreme sports: extreme physiology. Exercise-induced pulmonary oedema. Emerg Med Austral. 2013;25:368-71.

38. North VJ, Mansfield H. Images in emergency medicine: a case of acute breathlessness in a swimmer. Emerg Med J. 2013;30:429.

39. Casey H, Dastidar AD, Maclver D. Swimming-induced pulmonary oedema in two triathletesL a novel pathophysiological explanation. J Royal Soc Med. 2014;107(11):450-2.

40. Yamanashi H, Koyamatsu J, Nobuyoshi M, et al. Exercise-induced pulmonary edema in a triathlon. Case Rep Med. 2015:2015:968152.

41. Beale A, Gong FF, La Gerche A. Exercise-induced oedema in endurance triathletes. Int J Cardiol. 2016;203:980-1.

42. Shearer D, Mahon R. Brain natriuretic peptide levels in six basic underwater demolitions/SEAL recruits presenting with swimming induced pulmonary edema (SIPE). J Spec Ops Med. 2009;9(3):44-50.

43. Caillaud C, Serre-Cousine O, Anselme F, et al. Computerized tomography and pulmonary diffusing capacity in highly trained athletes after performing a triathlon. J Appl Physiol. 1995;79(4):1226-32.

44. Choi G, Kopplin LJ, Tester DJ, et al. Spectrum and frequency of cardiac channel defects in swimming-triggered arrhythmia syndromes. Circulation. 2004;110(15):2119-24.

45. Fraser JAV, Peacher DF, Freiberger JJ, et al. Risk factors for immersion pulmonary edema: hyperoxia does not attenuate pulmonary hypertension associated with cold water immersed prone exercise as 4.7 ATA.J Appl Physiol. 2011;110:610-8.

46. Harris KM, Henry JT, Rohman E, et al. Sudden death during the triathlon. JAMA. 2010;7(13):1255-7.

47. Pingitore $A$, Garbella $E$, Piaggi $P$, et al. Early subclinical increase in pulmonary water content in athletes performing heavy exercise at sea level: ultrasound lung comet-tail evidence. Am J Heart Circ Physiol. 2011;301: H2161-7.

48. Miller CC, Calder-Becker K, Modave F. Swimming-induced pulmonary edema in triathletes. Am J Emerg Med. 2010;28:941-6.

49. McKenzie DC, O'Hare TJ, Mayo J. The effect of sustained heavy exercise on the development of pulmonary edema in trained male cyclists. Respir Physiol Neurobiol. 2005;145:209-18.

50. Miles DS, Doerr CE, Schonfeld SA, et al. Changes in pulmonary diffusing capacity and closing volume after running a marathon. Respir Physiol. 1983; 52:349-59.

51. Eldridge MW, Severinghaus JW, Spellman MJ. Persistent pulmonary dysfunction following severe exercise at altitude (abstract). Int J Sports Med. 1992;13:83.

52. Asplund CA, Creswell LL. Hypothesised mechanisms of swimming-related death: a systematic review. Br J Sports Med. 2016;50:1360-6.

53. Shattock MJ, Tipton MJ. 'Autonomic conflict': a different way to die during cold. water immersion? J Physiol Lond. 2012;590:3219-30.

54. Hodges AN, Sheel AW, Mayo JR, et al. Human lung density is not altered following normoxic and hypoxic moderate-intensity exercise: implications for transient edema. J Appl Physiol. 2007;103:111-8.

55. Manier G, Duclos M, Arsac L, et al. Distribution of lung density after strenuous, prolonged exercise. J Appl Physiol. 1999;87:83-9.

56. Douglas PS, O'Toole ML, Katz SE, et al. Left ventricular hypertrophy in athletes. Am J Cardiol. 1997;15(80):1384-8.

57. Claessens $P$, Claessens $C$, Claessens $M$, et al. Ventricular premature beats in triathletes: still a physiological phenomenon? Cardiology. 1999;92:28-38.

58. Fuchs $T$, Torjman A, Galitzkaya $L$, et al. Do ventricular arrhythmias in athletes subside over time? Isr Med Assoc J. 2013;15(9):485-8.

59. Warburton DER, Welsh RC, Haykowsky MJ, et al. Effects of half ironman competition on the developments of late potentials. Med Sci Sports Exerc. 2000;32(7):1208-13. 